resenha de exposição]

[MARIANA CHRISTINA DE FARIA TAVARES RODRIGUES] Pesquisadora em História da Moda; mestre em Moda, Arte e Cultura; docente do Centro Universitário UNA (Belo Horizonte).

marianacftr@hotmail.com

\title{
Um ar de excelência
}

An air of excellence

Palais Galliera, Paris - Musée de la Mode de la Ville de Paris

Jeanne Lanvin

Curador: Olivier Saillard

De 8 de março a 23 de agosto de 2015. 
0 prédio do Musée de la Mode de la Ville de Paris (Museu da Moda Francesa), o Palais Galliera, já é por si só um espetáculo. Construído em estilo renascentista, possui colunatas e arcos bem definidos e um amplo pátio oval. Mas o principal acontece lá dentro.

A exposição Jeanne Lanvin, com direção criativa de Alber Elbaz, até então o bem-sucedido designer da marca', utilizou o acervo do museu para revelar a trajetória de Jeanne Lanvin (1867-1946), fundadora da maison de moda que se tornaria a mais longeva da história. Os trabalhos atuais da Maison Lanvin, por mais que tenham sido inspirados no passado, não participaram da mostra. Antes, porém, de falar sobre a exposição, vale conferir um pouco da história de madame Lanvin.

\section{Sobre Jeanne Lanvin}

Jeanne Lanvin não é uma figura tão conhecida dos leigos, como Chanel ou Christian Dior, mas em seu tempo, embora sempre tenha sido adepta do low profile, gozava de prestígio e credibilidade como uma das principais couturières da Paris do começo do século XX. E seu trabalho prova isso. Ela começou sua carreira como chapeleira em 1885. Já em 1889, abriu a loja Lanvin Modes na Rue Boissy d'Anglas, 16, e então, em 1893, adquiriu seu famoso endereço no número 22 da Rue du Faubourg Saint-Honoré (CATÁLOGO JEANNE LANVIN, PALAIS GALLIERA).

Em 1897, nasceu sua única filha, Marguerite ${ }^{2}$, que foi sua musa inspiradora pela vida afora e imortalizada no logotipo da marca. Em 1908, Lanvin iniciou um trabalho focado em roupas infantis que fez tanto sucesso que, em 1909, ela abriu um departamento para jovens e mulheres, desenhando roupas para mães $e$ filhas, como conjuntos composés. Até hoje o logotipo da loja, feito por Paul lribe ${ }^{3}$, representa mãe e filha.

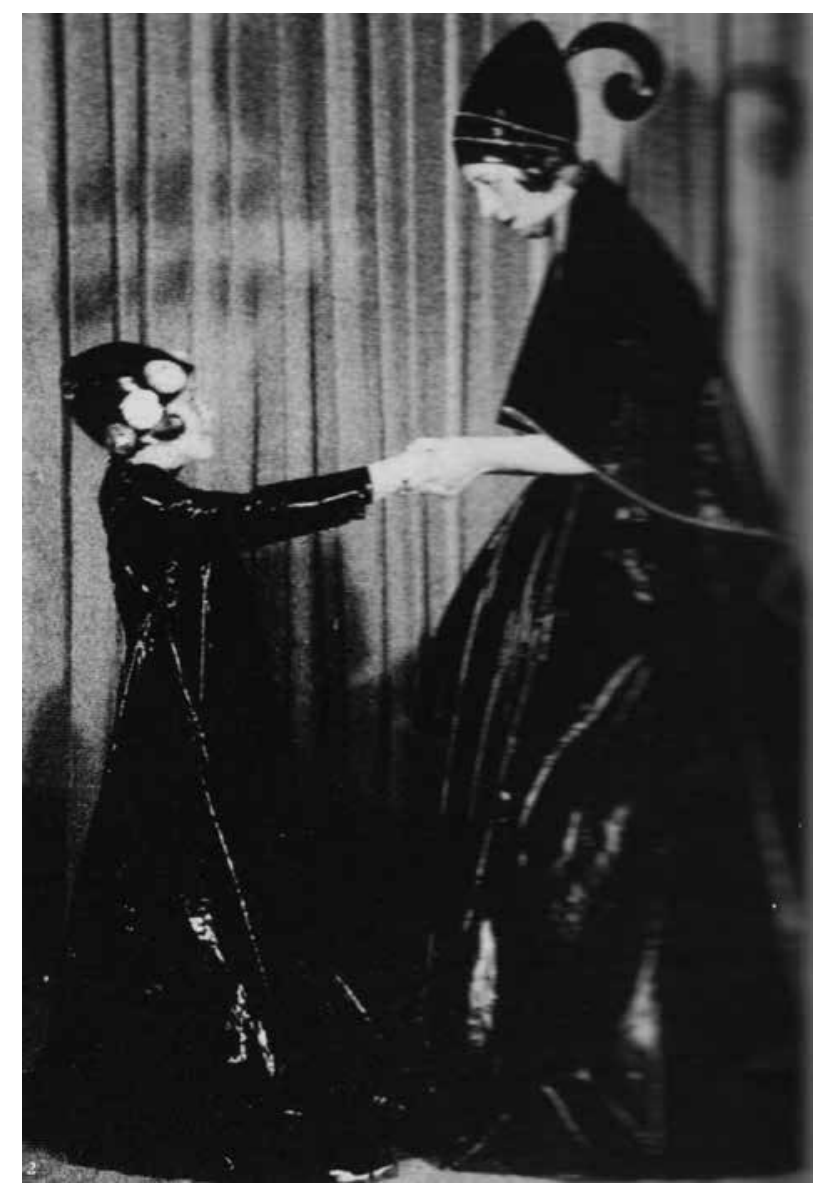

Figura 1 - A fotografia que inspirou Paul Iribe a criar o logotipo da Maison Lanvin. Fonte: Catálogo Jeanne Lanvin, Musée de la Mode de la Ville de Paris, 2015. 
Também em 1909, Lanvin une-se ao Sindicato da Costura Francesa, acrescentando mais credibilidade ao seu nome, e entra para o fechado mundo das maisons de moda francesa. A partir dai, o negócio prosperou e suas lojas foram ganhando departamentos: para noivas, peles, lingerie $e$, no começo dos anos 1920, decoração de interior e moda esportiva. Nesse período, Lanvin empregava cerca de 800 pessoas e criava 200 modelos de haute couture por coleção. Suas lojas espalhavam-se pelos locais frequentados pelo beau monde: Deauville, Biarritz, Cannes, Le Touquet, Barcelona, Buenos Aires (MUSÉE DE LA MODE DE LA VILLE DE PARIS, 2015). Em 1927, inspirada pelo trigésimo aniversário da filha Marguerite, criou o emblemático perfume Arpège, cuja embalagem traz o mesmo logotipo da loja (mãe e filha), e está à venda até hoje por cerca de 60 euros (MERCERON, 2007). Pode ser considerada a primeira marca com estilo único e identificável, que abrangia vestidos para mulheres e crianças, enxovais, moda esportiva, perfumaria, maquiagem e mobiliário para decoração. Embora não tenha sido adepta de uma moda ostentativa - procurava sempre o frescor da elegância -, Lanvin tinha uma grande e fiel clientela.

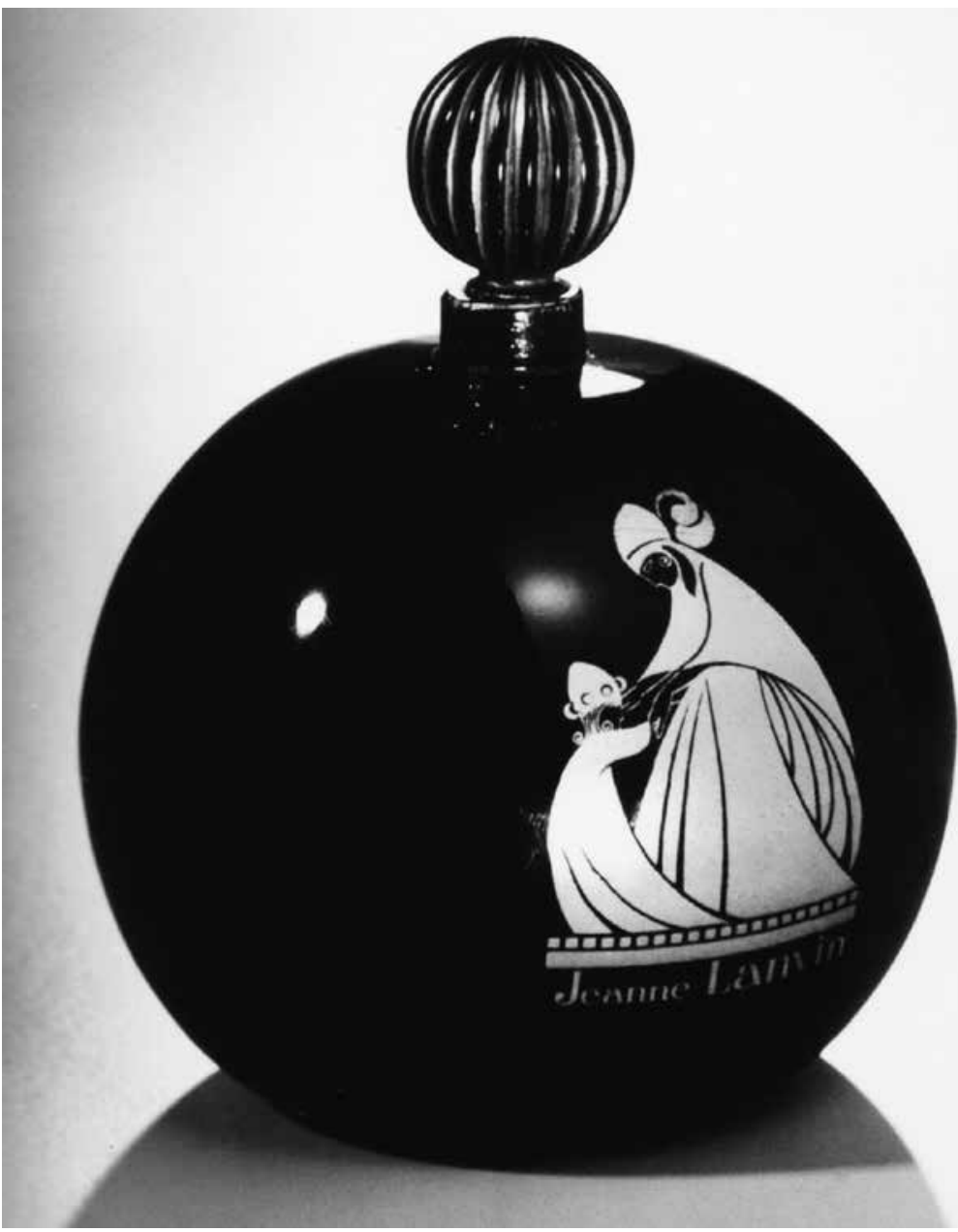

Figura 2 - Frasco e embalagem do perfume Arpège, de 1927.

Fonte: http://www.theperfumegirl.com/perfumes/fragrances/lanvin/lanvin-arpege/

\section{A exposição}

A exposição é aberta com base nos fundamentos conceituais que constituíram, e ainda constituem, a identidade da marca. Nela, pode-se ver os rascunhos 
para o logotipo (inspirado em uma fotografia de Lanvin e sua filha), itens de papelaria, etiquetas e uma série de fashion plates, todos feitos com uma especificidade de fontes e logotipos que unificava a materialização da marca. Depois, fixa-se nos anos mais importantes da carreira de Lanvin: 1910, 1920 e 1930. Cento e dez vestidos e casacos (sem contar os chapéus, croquis e arquivos) constituem a riqueza de uma obra singular.

Com vitrinas abertas nas laterais e mesas vitrinas com espelhos que refletem os objetos, possibilitando o exame dos detalhes, a exposição sobre Lanvin no Galliera foi um momento imperdivel para os interessados em moda, não só como um espetáculo de beleza, mas também, e principalmente, como uma ocasião para examinar detalhes da haute couture, aquilo que faz o seu nome e a diferencia do prêt-à-porter de luxo.

Seguindo uma linha do tempo, lá apareceram os chapéus de Lanvin, principalmente os famosos cloche, obra do comecinho de seu império, e os vestidos infantis. Vestidos de encantos, de fadas, decorados com fitas coloridas, flores de fitas, bordados de miçangas e fitas, para meninas da boa sociedade - mas que não impediam suas travessuras e traquinagens -, com saias rodadas que permitiam correr e pular. Como pode ser visto nas figuras 3 e 4, o estilo é lúdico e elegante, mas sem perder o toque infantil.

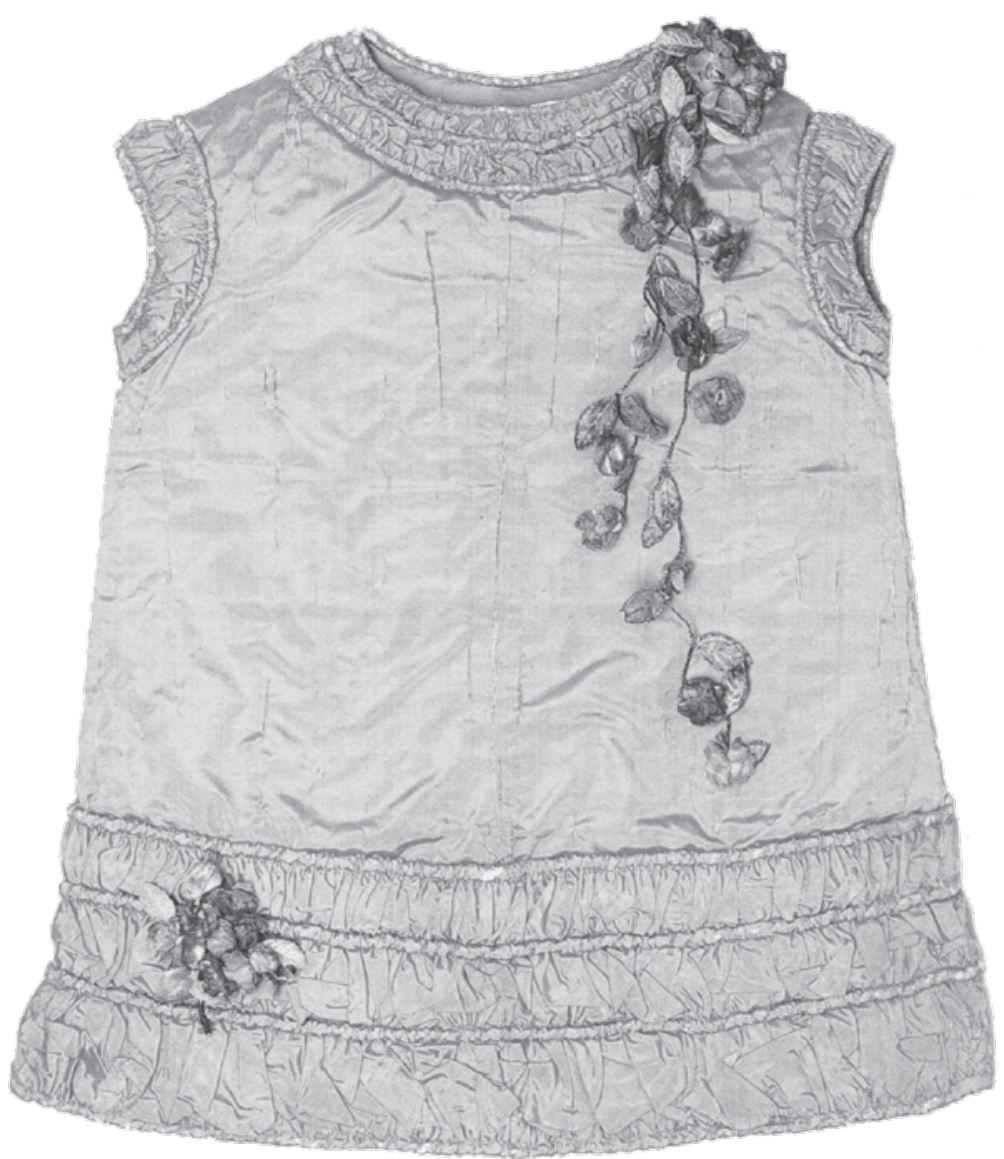

Figura 3 - Vestido infantil dos anos 1920.

Fonte: foto da autora. 


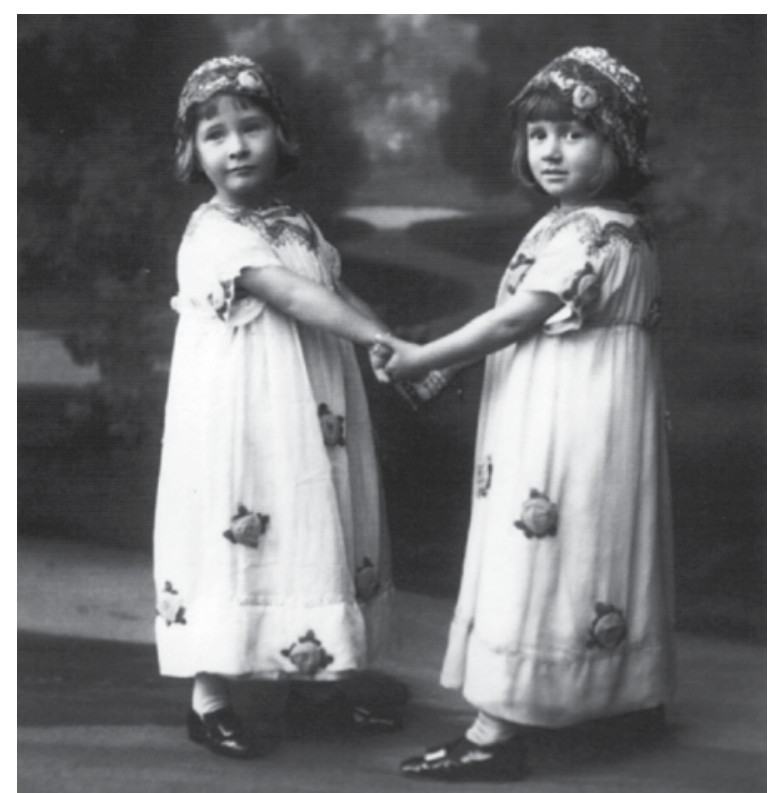

Figura 4 - Vestido infantil, 1923.

Fonte: MERCERON, 2007.

Os vestidos femininos são um caso à parte. A partir de 1910, pôde-se examinar os complexos designs de superfície feitos apenas com dobraduras de fitas de seda, bainhas aparentes bicolores feitas só com o uso de bobinas de duas cores diferentes em uma máquina de costura e a esmerada técnica do patchwork feita com um mesmo tecido, mas invertendo o sentido do fio em cada pedaço costurado (Figura 5).

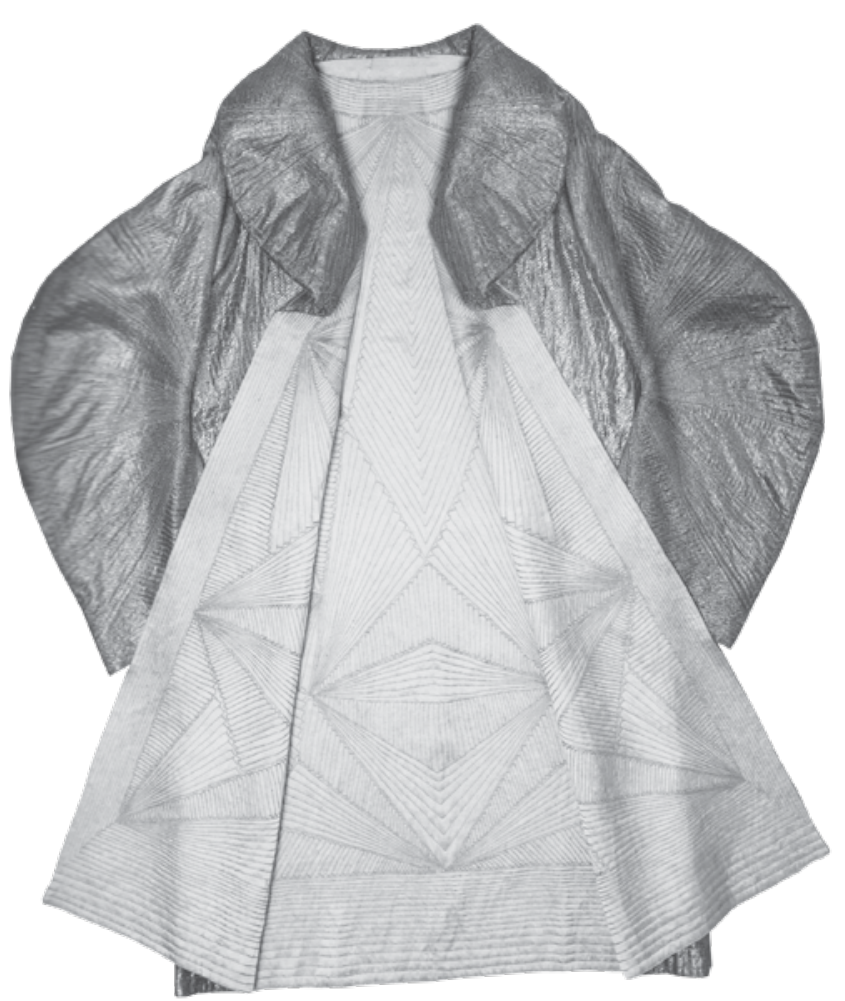

Figura 5 - Pelo avesso, fica mais fácil ver os pedaços de tecidos costurados com o fio invertido que constituem o casaco.

Fonte: Catálogo Jeanne Lanvin, Musée de la Mode de la Ville de Paris, 2015. 
Se as técnicas de modelagem de Lanvin empregam recortes apurados e 0 corte em viés, as aplicadas para adornar muitos de seus modelos são simples, independentes de alta tecnologia, mas apoiadas em um grande conhecimento de tecidos e de seu caimento no corpo feminino e um aparato de criatividade com os componentes de um ateliê de então. Que tal uma estampa abstrata feita apenas (e isso só é percebido quando nos aproximamos da peça em questão) com viés aplicado sobre o tecido?

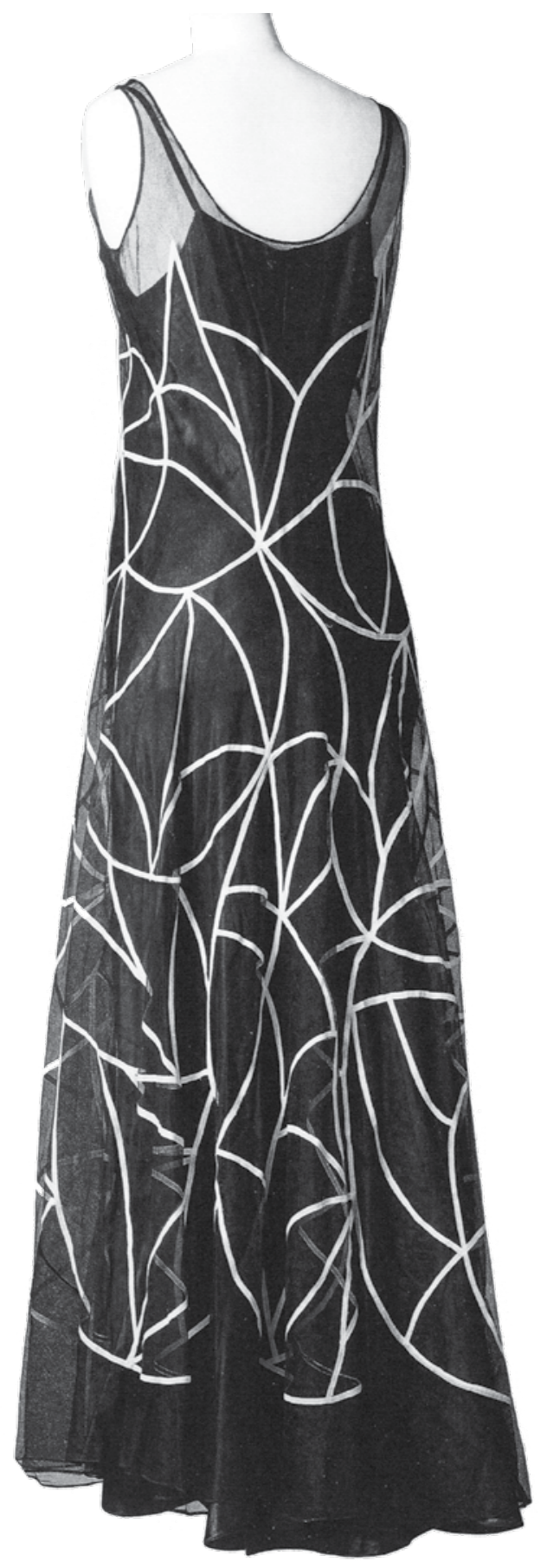


Bordados maravilhosos, coloridos e de tamanhos variados decoravam algumas roupas e, quando vistos de perto, percebia-se que eram feitos com ponto corrente, ou seja, um dos pontos mais comuns no bordado. Mas nem tudo era tão simples assim. Vários vestidos eram decorados com bordados mais rebuscados, com uso extensivo de cristais Swarovski e de dificil manufatura. Lanvin, provavelmente, tinha como fornecedora a qualificada mão de obra artesanal francesa, como a da Maison Lesage ${ }^{4}$, sua contemporânea, ou a de um de seus três próprios ateliês de bordado.

A grande maioria das obras de Lanvin possui uma grande atratividade, e os vestidos da década de 1930 podem ser tranquilamente usados no nosso contemporâneo. Deixam, na audiência, uma vontade de "eu queria tanto ter algo assim", que se torna assombroso constatar, em várias peças, pela simplicidade das ideias postas em prática para decorá-las, um testemunho de extrema criatividade e conhecimento de seu métier.

Embora não fosse uma exposição monocromática, a variação de cores era modesta, prevalecendo bege, preto e dourado, com poucos toques de vermelho, verde e amarelo. Entretanto, uma cor ressaltava aos olhos dos admiradores: 0 famoso azul Lanvin. Cor onipresente desde o começo do trabalho de Jeanne Lanvin, aparece tanto nas roupas femininas como nas infantis, nos acessórios e nos casacos mantôs. Era um azul de cor seca e tonalidade média, posteriormente chamado de azul Lanvin, foi a cor fetiche da couturière e se deve, provavelmente, às obras de Fra Angelico, como os vitrais de igrejas, atestando o local privilegiado da Renascença italiana no universo de Lanvin, como é explicado no catálogo da exposição (CATÁLOGO JEANNE LANVIN, PARIS GALLIERA).

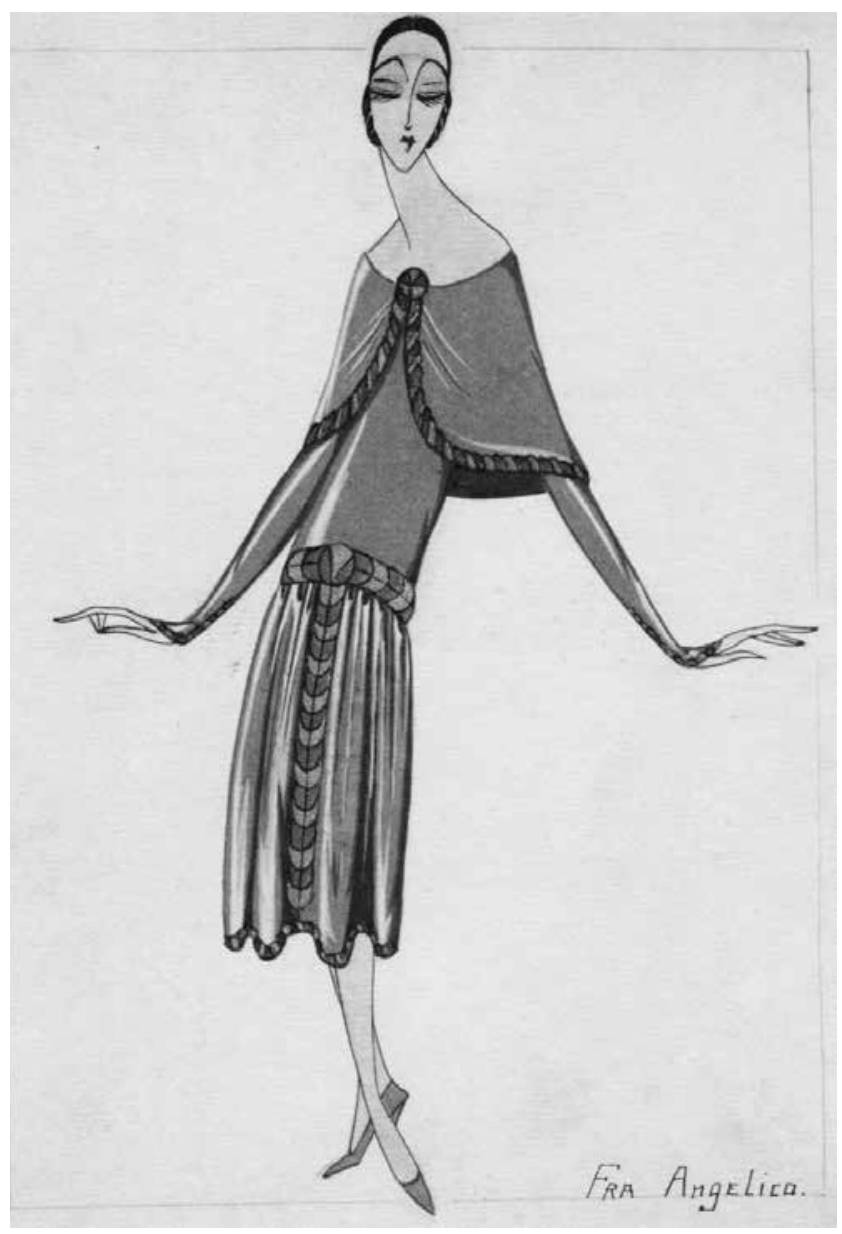

Figura 7 - 0 azul Lanvin no modelo Fra Angelico, da coleção de inverno de 1925. Fonte: Catálogo Jeanne Lanvin, Musée de la Mode de la Ville de Paris, 2015.

Do azul Lanvin aos tons de azul das porcelanas de Delfos, do lápis-lazúli ao índigo, uma gama de azuis é também utilizada, embora nada se compare à 
preferência pelo azul Lanvin, oficializada com a Lanvin Décoration, em 1921. Mais tarde, a cor fica muito conhecida por causa da decoração de seu quarto e boudoir, em sua casa particular na Rue Barbet-de-Jouy. Aliás, para os curiosos, esse pedacinho de Lanvin foi mantido pelo Musée des Arts Décoratifs du Louvre e pode ser visto ainda hoje em toda a sua glória e luminosidade.

0 interesse de Lanvin pelas cores era parte integrante de seu trabalho, o que a fez abrir em Nanterre, cidade francesa, uma tinturaria que produzia o colorido específico para o seu gosto e que pode ser visto no conjunto de suas roupas, mais eficientemente do que na exposição do Palais Galliera (CATÁLOGO JEANNE LANVIN, PALAIS GALLIERA).

Outro diferencial de Lanvin, plausivel de ser visto na exposição, é o robe de style, da década de 1920. Independentemente dos vestidos tubulares (que também produzia), Lanvin inspirou-se no passado, na historicidade do século XVIII, para trazer ao século XX vestidos de saias largas, apoiadas em paniers. É um estilo bem diferente do que se costuma ver nos filmes e seriados contemporâneos que se desenrolam nos anos 1920, que dão preferência ao flapper, reto, tubular. Entretanto, eram bem recebidos pelas clientes de Lanvin, que sempre os mantinha em suas coleções, variando suas proporções, e que foram posteriormente produzidos por outras maisons, como Boué Soeurs, Callot Soeurs e Worth. Extraordinária e possivelmente pelo profundo conhecimento dos figurinistas encarregados, o robe de style de Lanvin aparece em duas séries modernas: Downton Abbey ${ }^{5}$, na cena em que a debutante Rose ${ }^{6}$ é apresentada pela condessa de Grantham à família real inglesa, e na série Mr. Selfridge ${ }^{7}$, quando a personagem Viollete ${ }^{8}$, filha mais nova de mr. Selfridge, vai a um nightclub.

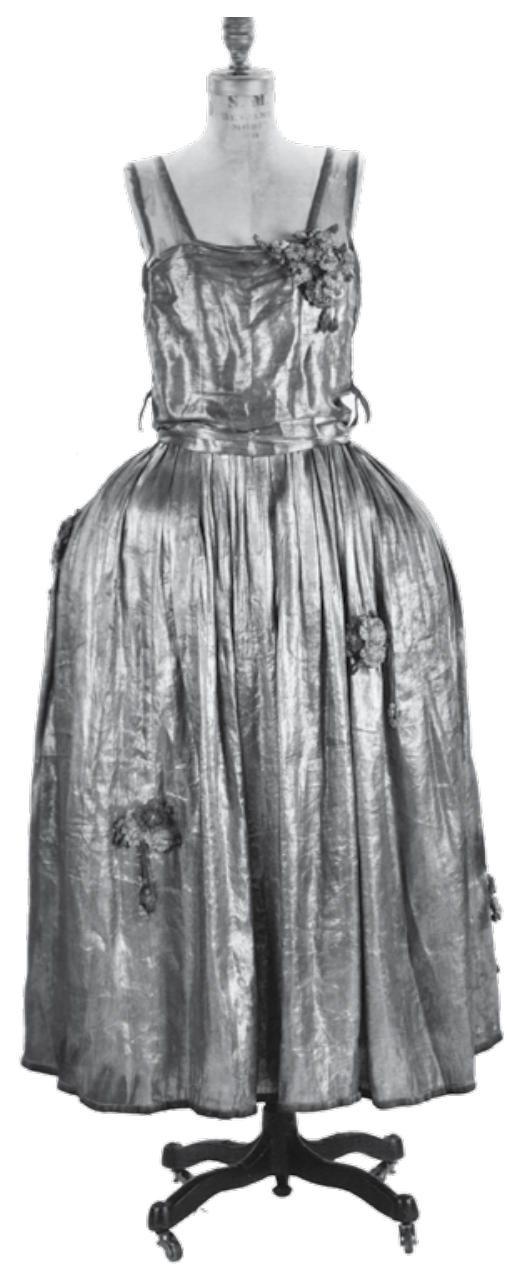


A exposição Jeanne Lanvin, de tão atraente, trazia em si uma quietude, aquela que mantém as pessoas absortas diante do que veem, de uma admiração que não carecia de gritos ou vozes altas, e sim de sentidos alertas para apurar todos os detalhes do que estava exposto. Se pudéssemos resumir em palavras, teríamos algo como delicadeza, leveza, frescor, detalhes, conforto, carinho, cuidado, gentileza, elegância; noções que permeavam o ar de excelência de Jeanne Lanvin.

\section{NOTAS}

[1] Alber Elbaz trabalhou na Maison Lanvin de 2001 a 2015, levando a marca para o mercado moderno da moda. Sua saída foi comentada na revista Elle, em 28/10/2015.

${ }^{[1]}$ Marguerite Marie Blanche di Peietro (1897-1958) assumiu a direção da Maison Lanvin após a morte da mãe, em 1946.

[3] Paul Iribe: ilustrador do começo do século XX, responsável também por inúmeros fashion plates da contemporânea e famosa Gazette du Bon Ton.

${ }^{[4]}$ A maison Lesage foi criada em 1924 e especializou-se em bordados. Ainda continua ativa, fazendo trabalhos para a alta-costura e o prêt-à-porter de luxo. É uma empresa referência em seu tipo de trabalho (nota do autor).

[5] Downton Abbey é um seriado britânico (2010 a 2015). Seu criador é Julian Felowes, também roteirista de Gosdorf Park, filme com a mesma temática (relações entre patrões e empregados das mansões de luxo inglesas). A figurinista dos episódios nos quais Rose aparece é Anna Robins (IMDB).

${ }^{\left[{ }^{[6]}\right.}$ Rose é interpretada pela atriz Lily James, que trabalhou também no seriado da BBC Guerra e Paz e, no cinema, fez Cinderela, do diretorKenneth Branagh (IMDB).

[7] Mr. Selfridgeé uma série (2013 a 2016) que conta a história do empresário homônimo, criador de uma das lojas de departamento mais luxuosa e tradicional de Londres, a Selfridges, que está aberta até hoje (IMDB).

${ }^{[8]}$ Viollete é a atriz Hannah Tointon. Os figurinos são de James Keats e Barbara Sweryda.(IMDB).

\section{REFERÊNCIAS}

ELLE. Disponivel em: <http://mdemulher.abril.com.br/moda/elle/alber-elbaz- anuncia-sua-saida-dalanvin>. Acesso em: 29 abr. 2016.

IMDB: http://www.imdb.com/.

MUSÉE DE LA MODE de la Ville de Paris, Palais Galliera. Jeanne Lanvin. Paris: Paris Museus, 2015.

MERCERON, Dean L. Lanvin. Nova York: Rizzoli Internacional Publication, 2007. 